\title{
Erratum to: Identification of Stachybotrys spp. by MALDI-TOF mass spectrometry
}

\author{
Sebastian Ulrich ${ }^{1} \cdot$ Barbara Biermaier $^{1}$ - Oliver Bader $^{2} \cdot$ Georg Wolf ${ }^{3}$. \\ Reinhard K. Straubinger ${ }^{3}$. Andrea Didier ${ }^{4}$ - Brigitte Sperner ${ }^{1}$. \\ Karin Schwaiger $^{1} \cdot$ Manfred Gareis $^{1} \cdot$ Christoph Gottschalk $^{1}$
}

Received: 31 August 2016/Accepted: 31 August 2016/Published online: 9 September 2016

(C) Springer-Verlag Berlin Heidelberg 2016

\section{Erratum to: Anal Bioanal Chem}

DOI 10.1007/s00216-016-9800-9

The original version of this article unfortunately contained a mistake. The mistake is in Table 2, page 10, Isolate FM27/14 under $\operatorname{RSD}(\%)$ there is a "q". The correct value under $\mathrm{RSD}(\%)$ is " 1.4 ". The original article was corrected.

The online version of the original article can be found at http://dx.doi. org/10.1007/s00216-016-9800-9.

Sebastian Ulrich

ulrich@1s.vetmed.uni-muenchen.de

1 Chair of Food Safety, Department of Veterinary Sciences, LMU Munich, Schoenleutnerstr. 8, 85764 Oberschleissheim, Germany

2 Institute for Medical Microbiology, University Medical Center Goettingen, Kreuzbergring 57, 37075 Goettingen, Germany

3 Chair of Microbiology and Mycology, Department of Veterinary Sciences, LMU Munich, Veterinaerstr. 13, 80539 Munich, Germany

4 Chair for Hygiene and Technology of Milk, Department of Veterinary Sciences, LMU Munich, Schoenleutnerstr. 8, 85764 Oberschleissheim, Germany 